CAHIER DE RECHERCHE \#1108E

Département de science économique

Faculté des sciences sociales

Université d'Ottawa
WORKING PAPER \#1108E

Department of Economics

Faculty of Social Sciences

University of Ottawa

\title{
Conditional Cash Transfers and Education Quality in the Presence of Credit Constraints
}

\author{
Elena Del Rey ${ }^{\dagger}$ and Fernanda Estevan ${ }^{\ddagger}$
}

August 2011

\footnotetext{
${ }^{*}$ We gratefully acknowledge the hospitality of the University of Girona and the University of Ottawa and financial support from the Spanish Ministry of Science and Innovation through Research Grant ECO2010-16353, the Autonomous Government of Catalonia through Research Grant 2009SGR-189 and XREPP. We are indebted to Pierre Brochu, Jana Hromcová, Christopher Ksoll, and participants at the 2010 CEPR Development Economics Workshop Pre conference (Barcelona) and the 2011 CEA Meeting (Ottawa) for their insightful comments. We retain responsibility for any remaining errors.

† Corresponding author: FCEE, University of Girona, Campus de Montilivi, 17071 Girona, Spain; E-mail: elena.delrey@udg.edu.

${ }^{*}$ Department of Economics, University of Ottawa, 55 Laurier E., Ottawa, Ontario, Canada, K1N 6N5; Email: Fernanda.Estevan@uottawa.ca.
} 


\begin{abstract}
We investigate the relative merits of unconditional cash transfers (UCT), conditional cash transfers (CCT), and improvements in education quality on efficiency and welfare. In our setting some parents under-invest in their children's education because capital market imperfections prevent them from borrowing. When credit constrained households can be perfectly targeted by the government, we show that CCT are more effective than UCT in enhancing efficiency and equivalent in terms of welfare. When public education quality is very low, raising quality is welfare improving, but is never efficiency enhancing. If the government cannot target constrained households, UCT may be the best policy both in terms of efficiency and welfare.
\end{abstract}

Key words: conditional cash transfers, public education, education quality, unconditional cash transfers, credit constraint, efficiency, welfare.

JEL Classification: H31, H42, H52.

\title{
Résumé
}

Nous étudions les avantages relatifs des transferts monétaires inconditionnels (UCT), des transferts monétaires conditionnels (CCT) et de l'amélioration de la qualité de l'éducation sur l'efficacité et le bienêtre. Dans notre modèle, certains parents sous-investissent dans l'éducation de leurs enfants parce que des imperfections du marché de crédit les empêchent d'emprunter. Lorsque les ménages confrontés à des restrictions du crédit peuvent être parfaitement ciblés par le gouvernement, nous montrons que les CCT ont un impact plus important en termes d'efficacité que les UCT et sont équivalents en termes de bienêtre. Lorsque la qualité de l'éducation est très faible, l'amélioration de la qualité augmente le bien-être mais ne peut pas améliorer l'efficacité. Si le gouvernement ne peut pas cibler les ménages contraints monétairement, les UCT peuvent être la meilleure politique à la fois en termes d'efficacité et de bien-être.

Mots clés: transferts monétaires conditionnels, éducation publique, qualité de l'éducation, transferts monétaires inconditionnels, restrictions du crédit, efficacité, bien-être.

Classification JEL: H31, H42, H52. 


\section{Introduction}

Conditional cash transfers (CCT) have been extensively implemented in developing countries since the 1990s. These programs provide low-income households with incentives to send their children to school by tying a cash transfer to school attendance. ${ }^{1}$ The Mexican Oportunidades and the Brazilian Bolsa Familia constitute well-known examples of CCT programs.

To justify the implementation of CCT programs, the literature has focused on the existence of social externalities (de Janvry and Sadoulet (2004)), individual irrationality, impatience, or lack of self-control (Das et al. (2005)). ${ }^{2}$ Under these circumstances, it is well-known that conditional transfers have a larger impact on individual behavior, but are never superior in terms of utility to unconditional transfers. In contrast, little is known about the effect of CCT when poverty, combined with the inability to borrow, is the underlying reason for under-investing in education, as noted in Das et al. (2005) and Martinelli and Parker (2003).

The large empirical literature evaluating CCT confirms that these programs boost school enrollment and decrease drop-out rates. ${ }^{3}$ However, an often-raised concern regarding CCT is that the increase in school enrollment may not be the most effective way to raise human capital. Indeed, the impact of CCT in terms of learning is not obvious, since education quality is typically low in countries adopting CCT (e.g. Lockheed and Verspoor (1991), Hanushek (1995), Glewwe (1999), Reimers et al. (2006)). Thus, a natural question is whether increasing quality would in fact have a larger impact on human capital, as suggested by Bourguignon et al. (2003) and Martinelli and Parker (2003), and, more generally, on lifetime income (efficiency) and utility (welfare). ${ }^{4}$

In this paper, we consider a two-period model based on Baland and Robinson (2000) where parents under-invest in education because they are credit constrained. In addition, we explicitly account for the role of education quality on human capital formation. In our setting, the government provides education free of charge for constrained households, but this is not sufficient to induce the efficient amount of time at school. This allows us to

\footnotetext{
${ }^{1}$ In this paper, we focus exclusively on the education component of these programs. Most CCT programs also condition on regular check-ups and some also include a nutrition counterpart. For a review of CCT programs, see Das et al. (2005) and Rawlings and Rubio (2005).

${ }^{2}$ Another rationale for CCT is intra-household bargaining, as discussed in Martinelli and Parker (2003).

${ }^{3}$ Examples of empirical papers focusing on the education component of CCT programs include Attanasio et al. (2005), Behrman et al. (2005), Coady and Parker (2004), de Brauw and Hoddinott (2010), Dubois et al. (2008), Ferreira et al. (2009), Maluccio and Flores (2005), Schady and Araujo (2006), Schultz (2004), Skoufias and Parker (2001), Souza and Cardoso (2009), and Todd and Wolpin (2006).

${ }^{4}$ Education quality can be raised by increasing school inputs, such as school facilities or teacher qualification. For a comprehensive discussion on education quality, see Hanushek (2006) and Hanushek and Rivkin (2006).
} 
explore the relative merits of cash transfers (conditional and unconditional) and investments in education quality in terms of efficiency and welfare in the presence of credit constraints. More specifically, we consider the effect of marginal changes in each of the policy parameters separately when the three policies are in place. Hence, our approach is positive and aims at exploring the relative merits of several commonly used policy instruments.

In our model there are two inputs, time spent at school and education quality, which can be substitutes or complements in the human capital production function. ${ }^{5}$ Parents choose the fraction of time their children spend at school during childhood by considering the impact of that decision on household utility. ${ }^{6}$ Since CCT are usually paid on a monthly basis over several years, we model time spent at school as a continuous variable. Each unit of time the child spends at school generates costs in the first period related to tuition fees, foregone child labor earnings, and other indirect costs such as clothing, materials, and transportation. In return, it increases household income in the second period. We assume that some households do not have the means to defray the costs in the first period. Since credit market imperfections prevent them from borrowing, their children spend an inefficiently low amount of time at school for any given level of education quality.

Unconditional cash transfers (UCT) are a natural instrument to recover efficiency when poverty is the reason why households under-invest in education. By increasing household income in the first period, UCT lead credit constrained households to increase the time their children spend at school. However, it is unclear whether UCT are more or less effective than CCT in enhancing efficiency. Indeed, in the presence of market imperfections, distorting individual behavior by imposing conditions may be more desirable (Lipsey and Lancaster (1956)). We contribute to this debate by investigating, first, the relative effect in terms of efficiency of UCT and CCT. Second, we explore the conditions under which policies that improve education quality prove more adequate to recover efficiency. Finally, we also evaluate the different policies from a welfare viewpoint.

We obtain the following results. When constrained households can be perfectly targeted, CCT are more efficiency enhancing than UCT, as in the previous literature. In contrast, in our framework, both cash transfers are equivalent in terms of welfare. This happens for two

\footnotetext{
${ }^{5}$ Whether time spent at school and education are complements or substitutes is ultimately an empirical question. To our knowledge little research has been done on this topic. An exception, in a slightly different framework, is Aker and Ksoll (2011).

${ }^{6} \mathrm{By}$ focusing on household utility, we allow for inter-generational transfers without explicitly accounting for these decisions. When inter-generational transfers are interior, considering household utility (as here) or the utility of the parent and the child separately (as in Baland and Robinson (2000)) yields identical results.
} 
reasons. First, if households were not credit constrained, their choices would be optimal. ${ }^{7}$ Second, CCT change the unit price of education over the lifetime and allow households to adjust their behavior at the margin. These results change when constrained households cannot be targeted. In particular, given that children in constrained households spend less time at school than those in unconstrained households, the former receive less income under CCT than UCT. This undermines the positive effects of CCT on efficiency and makes UCT superior to CCT in terms of welfare for constrained households.

We also show that raising education quality increases welfare when education quality is inefficiently low. Surprisingly, when quality is very low, improving education quality is never efficiency enhancing. Since the marginal productivity of education quality is very large when quality is very low, households can significantly decrease the time their children spend at school and still attain the same level of income in the second period when education quality increases. When education quality approaches its optimal level, improving quality becomes efficiency enhancing under rather general conditions. Households then respond by increasing or decreasing the time their children spend at school, depending on the human capital technology. However, increasing quality not only affects households decisions, but also changes the amount of time spent at school required to maximize lifetime income (i.e., the efficient level of education). If education quality and time spent at school are substitutes or weak complements, we show that the efficient and actual amount of time spent at school come closer, reducing the inefficiency of credit constrained households decisions.

Finally, the effect of improving quality on efficiency and welfare of constrained households does not change when unconstrained households also benefit from free tuition. However, free tuition induces over-investment in education by unconstrained households, and increasing education quality does not improve the efficiency of this decision.

The rest of the paper is organized as follows. Section 2 presents the model and the alternative policies, identifies the first best, and the credit constrained solution. Our main results are based on the case where the government is able to target constrained households. Sections 3 and 4 respectively evaluate the effects of revenue neutral changes in the policies in terms of efficiency and welfare. In Section 5, we reconsider the policies in a setting where the government is not able to target constrained households. Section 6 concludes.

\footnotetext{
${ }^{7}$ This is a consequence of the absence of externalities and the fact that households are not irrational or impatient.
} 


\section{The Model}

A household is composed of one parent and one child and lives for two periods. The parent is endowed with $a$ units of efficient labor (or units of human capital) and the child is endowed with 1 unit of efficient labor. The wage per unit of efficient labor is $w$, determined exogenously in competitive markets.

In the first period, the parent works, supplying inelastically her efficient labor. She decides on the allocation of her child's time between school, $e$, and work $1-e$, and on the amount of savings $s$. These are the only economic decisions, made by the parent in the first period, and they determine household consumption of the numeraire good in the first and second periods.

We assume the existence of a public school that transforms $q$ units of the numeraire into one unit of education of quality $q$ (Besley and Coate (1991)). We first consider the benchmark case where the government sells this education at market prices. In this case, the cost of acquiring $e$ units of education is the sum of tuition costs qe, earnings forgone by children we, and other indirect costs of education such as transportation, books or clothing $\kappa e$. Households consume $c_{1}$ and save $s$.

In the second period, the child (now an adult) works supplying $h(e, q)$ efficiency units of labor. The function $h$ is twice continuously differentiable, strictly increasing, and strictly concave in its two arguments. We assume that $\lim _{q \rightarrow 0} h_{q}(e, q)=\infty$, where the subscript denotes the variable with respect to which the function is differentiated. This assumption is extreme and implies that increasing quality has a large effect on human capital, making a case for increasing quality, when quality is very low. ${ }^{8}$ We allow for $e$ and $q$ to be complements, $h_{e q}(e, q)>0$, or substitutes, $h_{e q}(e, q)<0 .{ }^{9}$ Consumption in the second period, $c_{2}$, is the sum of the parent's savings and the child's labor income, wh $(e, q)$.

Finally, capital markets are imperfect, so that parents can save but cannot borrow, i.e., $s \geqslant 0$. When the parental endowment of efficient labor $a$ is low, households are credit constrained, and their only source of revenue in the second period is the child's labor income. When $a$ is large, households are unconstrained. We denote $a_{c}$ and $a_{u}$ the endowment of a constrained and unconstrained household respectively. There is a mass of households of size 1 and $\lambda$ is the proportion of households with low parental endowment.

There are three policies aimed at constrained households: an unconditional cash transfer $(\mathrm{UCT}) v$, a conditional cash transfer (CCT) $\theta e$, and a per unit of education tuition sub-

\footnotetext{
${ }^{8}$ Yet, as it will be made clear in Section 3, when quality tends to zero, increasing quality reduces efficiency.

${ }^{9}$ This corresponds to the concept of q-complements and q-substitutes defined by Hicks (1970).
} 
sidy $f e{ }^{10}$ In Sections 3 and 4, we restrict the analysis to the effect of these policies on constrained households. Finally, in Section 5 we discuss the implications of making these policies universal. ${ }^{11}$

Public policies are financed by government debt in the first period. ${ }^{12} \mathrm{~A} \operatorname{tax} T$ is paid by all households in the second period. ${ }^{13}$ In order to simplify notation, we assume that agents receive zero interest rate for their savings and that they do not discount future utility. The government budget constraint is given by:

$$
T=\lambda\left(v+\theta e_{c}+q e_{c}\right)
$$

where $e_{c}$ is the time spent at school by credit constrained households.

We assume that all policies are in place and we evaluate the effect of raising UCT, CCT, and education quality that is provided free of charge to families. We assume that the government will only increase $q$ if the marginal benefit is larger than the marginal cost and we restrict our analysis to this case. Our view is that this is also a reasonable assumption in countries characterized by low education quality, as those having adopted conditional cash transfers (e.g. Bourguignon et al. (2003) and Martinelli and Parker (2003)).

Assumption 1 The benefit of increasing education quality is larger than its tax cost for any given choice of time spent at school.

When free tuition is targeted to constrained individuals, this assumption can be written as $w h_{q}\left(e_{c}, q\right)-\lambda e_{c}>0$. By the assumptions on the human capital technology, this difference is larger (smaller) the smaller (larger) is $q$. When $w h_{q}\left(e_{c}, q\right)-\lambda e_{c}=0, q$ is optimal from the point of view of the government, since it maximizes the difference between the income and the tax costs generated by education.

We now turn to the parents' choice of $e$ and $s$. Household utility is denoted:

$$
U_{i}=U\left(c_{1 i}\right)+U\left(c_{2 i}\right)
$$

\footnotetext{
${ }^{10} \mathrm{It}$ is convenient to distinguish the CCT from the tuition subsidy, since we will concentrate on the case of free tuition for the constrained households, i.e. $f=q$.

${ }^{11}$ Gahvari and Mattos (2007) deal with the optimal design of CCT in the presence of information asymmetries.

${ }^{12}$ This is the most favorable scenario since a tax in the first period would tighten even more the budget of constrained households. We have, however, verified that the timing of taxes does not change our main results. The qualitative results also remain unchanged if no taxes are levied and the funds come from external sources.

${ }^{13}$ This redistributive aspect of the policy does not affect our qualitative results. The case in which there is no redistribution can be easily derived by making $\lambda=1$.
} 
where the subindex $i=\{c, u\}$ denotes whether the household is constrained or unconstrained, and:

$$
\begin{gathered}
c_{1 i}=w a_{i}+w(1-e)-\kappa e-q e+f e+v+\theta e-s \\
c_{2 i}=s+w h(e, q)-T
\end{gathered}
$$

Parents maximize (2) with respect to $e$ and $s$, subject to (3) and (4), and the constraint that $s \geq 0$. First order conditions are sufficient for maximization since the second order conditions are satisfied. When choosing $e$, parents equalize the marginal cost and the marginal benefit of spending time at school in terms of household utility:

$$
(w+\kappa+q-f-\theta) U^{\prime}\left(c_{1 i}\right)=w h_{e}\left(e_{i}, q\right) U^{\prime}\left(c_{2 i}\right) \text { and } e_{i}>0
$$

assuming that there is an interior optimal solution for $e$ when $\theta<w+\kappa+q-f$. Thus, we restrict our analysis to the cases where the CCT does not cover all the costs related to education, as supported by empirical evidence (e.g. Schultz (2004)). If they do, the optimal choice of $e$ is 1 .

The optimal choice of $s$ is given by:

$$
\begin{aligned}
& U^{\prime}\left(c_{2 u}\right)=U^{\prime}\left(c_{1 u}\right) \text { and } s_{u}>0 \\
& U^{\prime}\left(c_{2 c}\right)<U^{\prime}\left(c_{1 c}\right) \text { and } s_{c}=0
\end{aligned}
$$

When households are unconstrained, saving allows them to equalize marginal utility in both periods. When they are credit constrained, savings are zero and the marginal utility of first period consumption is larger: Parents would like to borrow, but are prevented from doing so by credit market imperfections.

\subsection{First Best}

The first best is the benchmark case where $v=\theta=f=T=0$ and capital markets are perfect. When the savings choice is interior we combine (5) and (6) to obtain:

$$
w h_{e}\left(e_{u}, q\right)=(w+\kappa+q)
$$

for a given $q$. Condition (8) characterizes the amount of time spent at school that maximizes households' lifetime income, i.e., the efficient level of $e$. This is given by the equality between 
the marginal benefit, $w h_{e}(e, q)$, and the marginal cost of time spent at school, $(w+\kappa+q)$. Thus, for unconstrained households, the decision concerning education investment maximizes utility and it is efficient.

\subsection{Credit Constrained Solution without Government}

When households are too poor and unable to borrow, their children spend an inefficiently low amount of time at school, as in Baland and Robinson (2000). Indeed, combining (5) and (7):

$$
w h_{e}\left(e_{c}, q\right)>(w+\kappa+q) .
$$

Since the marginal benefit of time spent at school is larger than its marginal cost, households could increase lifetime income by raising $e$. This would require transferring income from the second to the first period to cover education costs. However, the borrowing constraint prevents them from doing so.

\section{$3 \quad$ Efficiency}

In this section, we explore the relative merits of alternative policies in enhancing efficiency in the education decision of credit constrained households. We define:

$$
I_{c}=w h_{e}\left(e_{c}, q\right)-(w+\kappa+q)>0,
$$

as the inefficiency of the decision concerning time spent at school by constrained households. ${ }^{14}$

We assume that tuition is free for constrained households. With free tuition, the choice of time spent at school by constrained parents is $w h_{e}\left(e_{c}, q\right)>(w+\kappa)$. Therefore, $I_{c}=0$ if and only if $w h_{e}\left(e_{c}, q\right)-(w+\kappa)=q$. For the sake of interest, we assume $w h_{e}\left(e_{c}, q\right)-(w+\kappa)>q$, that is, constrained households under-invest in their children's education even if it is tuition free. Otherwise, either household behavior would already be efficient, or the government could simply reduce the subsidy in order to recover efficiency.

\footnotetext{
${ }^{14}$ Using (5) and (7), we obtain $w h_{e}\left(e_{c}, q\right)=(w+\kappa+q) \frac{U^{\prime}\left(c_{1 c}\right)}{U^{\prime}\left(c_{2 c}\right)}>(w+\kappa+q)$, since the household is constrained, i.e. $U^{\prime}\left(c_{1 c}\right)>U^{\prime}\left(c_{2 c}\right)$. Although there are in principle two ways of enhancing efficiency, lowering $\frac{U^{\prime}\left(c_{1 c}\right)}{U^{\prime}\left(c_{2 c}\right)}$ or $w h_{e}\left(e_{c}, q\right)-(w+\kappa+q)$, they are univocally related, and both approaches yield similar qualitative results.
} 
We now analyze alternative policies - UCT, CCT, and improvements in education quality - that may enhance efficiency in the parents' decisions concerning education. We investigate the effect of marginal changes in each of the policy parameters separately when the three policies are in place. This allows us to consider marginal changes from one policy to the other such that the government budget constraint is kept balanced.

\subsection{Cash Transfers}

An increase in UCT reduces the inefficiency of the constrained household decisions:

$$
\frac{d I_{c}}{d v}=w h_{e e}\left(e_{c}, q\right) \frac{d e_{c}}{d v}<0
$$

since, by (5) and the implicit function theorem, when $s=0:^{15}$

$$
\frac{d e_{c}}{d v}=-\frac{-(w+\kappa-\theta) U^{\prime \prime}\left(c_{1 c}\right)-w h_{e}\left(e_{c}, q\right) \lambda U^{\prime \prime}\left(c_{2 c}\right)}{(w+\kappa-\theta)^{2} U^{\prime \prime}\left(c_{1 c}\right)+\left(w h_{e}\left(e_{c}, q\right)\right)^{2} U^{\prime \prime}\left(c_{2 c}\right)+w h_{e e}\left(e_{c}, q\right) U^{\prime}\left(c_{2 c}\right)}>0 .
$$

By increasing income in the first period, an increase in UCT reduces the marginal utility of first period consumption and, by (5), the marginal cost of investing in education. Conversely, an increase in UCT reduces income in the second period through higher taxes, thereby increasing the marginal utility in the second period and thus the marginal benefit of time spent at school. As a result, an increase in UCT always increases the amount of time that the child spends at school, reducing the inefficiency of the education decision. Note that the effect on the behavior of constrained households is intrinsically related to the relaxation of the credit constraint: even if UCT received equal taxes paid, the inefficiency is reduced.

We now show that an increase in CCT reduces the inefficiency of the constrained household decisions:

$$
\frac{d I_{c}}{d \theta}=w h_{e e}\left(e_{c}, q\right) \frac{d e_{c}}{d \theta}<0
$$

since, proceeding as before:

$$
\frac{d e_{c}}{d \theta}=-\frac{U^{\prime}\left(c_{1 c}\right)-(w+\kappa-\theta) e_{c} U^{\prime \prime}\left(c_{1 c}\right)-w h_{e}\left(e_{c}, q\right) \lambda e_{c} U^{\prime \prime}\left(c_{2 c}\right)}{(w+\kappa-\theta)^{2} U^{\prime \prime}\left(c_{1 c}\right)+\left(w h_{e}\left(e_{c}, q\right)\right)^{2} U^{\prime \prime}\left(c_{2 c}\right)+w h_{e e}\left(e_{c}, q\right) U^{\prime}\left(c_{2 c}\right)}>0 .
$$

Similar to the UCT, the increase in CCT raises the marginal benefit and reduces the marginal

\footnotetext{
${ }^{15}$ Since $s=0$, we only need to study the marginal effects on the education decision through (5).
} 
cost in terms of utility, leading to more time spent at school. As before, these effects alleviate the credit constraint. Moreover, the reduction in the marginal cost is now enhanced by the reduction in the price of education due to $\theta$.

Proposition 1 Conditional cash transfers are always more effective than unconditional cash transfers in reducing the inefficiency of credit constrained households' decisions when they can be targeted.

Proof. An increase in CCT compensated by a reduction in UCT that keeps the government budget constraint balanced requires:

$$
d v=-e_{c} d \theta
$$

from (1). The total effect of this change on inefficiency is given by $\Upsilon_{c}^{\theta, v}=\frac{d I_{c}}{d \theta} d \theta+\frac{d I_{c}}{d v} d v$. Using (13):

$$
\Upsilon_{c}^{\theta, v}=h_{e e}\left(e_{c}, q\right)\left(\frac{d e_{c}}{d \theta}-\frac{d e_{c}}{d v} e_{c}\right) d \theta
$$

Plugging (11) and (12) into (14):

$$
\Upsilon_{c}^{\theta, v}=-\frac{h_{e e}\left(e_{c}, q\right) U^{\prime}\left(c_{1 c}\right) d \theta}{(w+\kappa-\theta)^{2} U^{\prime \prime}\left(c_{1 c}\right)+\left(w h_{e}\left(e_{c}, q\right)\right)^{2} U^{\prime \prime}\left(c_{2 c}\right)+w h_{e e}\left(e_{c}, q\right) U^{\prime}\left(c_{2 c}\right)}<0 .
$$

CCT are clearly more distortive than UCT since they are conditioned on behavior. Still, in line with the Theory of the Second Best (Lipsey and Lancaster (1956)), in the presence of market imperfections, it turns out to be desirable to introduce additional distortions. Indeed, Proposition 1 shows that CCT are more effective in reducing inefficiency than UCT, for households that are credit constrained and can be perfectly targeted.

\subsection{Education Quality}

Since all children attend the same school system, any policy affecting education quality necessarily affects both constrained and unconstrained households. However, increasing $q$ has different implications for constrained households, who do not pay tuition fees, and unconstrained households, who bear the full cost of education. In terms of efficiency, we show in Appendix A that unconstrained households decisions concerning time spent at school are efficient and remain efficient following an increase in $q$, provided that they are not entitled to free tuition. 
For credit constrained households, differentiating (9) with respect to $q$, we find:

$$
\frac{d I_{c}}{d q}=w h_{e q}\left(e_{c}, q\right)-1+w h_{e e}\left(e_{c}, q\right) \frac{d e_{c}}{d q} .
$$

In contrast to UCT and CCT, an increase in quality alters the efficient level of time spent at school itself, i.e., the amount of time spent at school required to maximize lifetime income. This can be seen in the two first terms in (15). The cross derivative $h_{e q}(e, q)$ is the direct effect of quality on the marginal productivity of time spent at school. It is positive (negative) when time spent at school and education quality are complements (substitutes), implying that the efficient level of $e$ increases (decreases) following the increase in $q$. Thus, for a given choice of $e$, the inefficiency increases (decreases) due to this first term. The second term in (15) represents the larger cost attached to providing higher education quality. By raising the marginal cost of $e$, this effect unambiguously decreases the inefficiency of a given choice of $e$.

The effects of $q$ on $I_{c}$ through the first two terms in (15) can be summarized as follows. If $e$ and $q$ are substitutes, an increase in $q$ unambiguously reduces the efficient level of $e$, reducing the inefficiency of the education decision for a given choice of $e$. Then, a higher $q$ allows households to maximize lifetime income with less time spent at school. Even if there is no change in behavior, the inefficiency is reduced. If $e$ and $q$ are complements, the effect of $q$ on the efficient level of $e$ is ambiguous. On the one hand, a larger $q$ requires more time spent at school to attain efficiency. On the other hand, it increases the marginal cost of education, and therefore reduces the difference between marginal benefit and marginal cost.

In addition, the complementarity or substitutability of $e$ and $q$ also affects the choice of $e$ when $q$ increases (last term in (15)). In the case of constrained households, by (5) and the implicit function theorem with $s=0$ :

$$
\frac{d e_{c}}{d q}=-\frac{w h_{e q}\left(e_{c}, q\right) U^{\prime}\left(c_{2 c}\right)+\left(w h_{q}\left(e_{c}, q\right)-\lambda e_{c}\right) w h_{e}\left(e_{c}, q\right) U^{\prime \prime}\left(c_{2 c}\right)}{(w+\kappa-\theta)^{2} U^{\prime \prime}\left(c_{1 c}\right)+\left(w h_{e}\left(e_{c}, q\right)\right)^{2} U^{\prime \prime}\left(c_{2 c}\right)+w h_{e e}\left(e_{c}, q\right) U^{\prime}\left(c_{2 c}\right)} .
$$

If $e$ and $q$ are substitutes, an increase in $q$ unambiguously decreases the time spent at school chosen by constrained households. If they are complements, there are two opposite effects on time spent at school. First, households have an incentive to increase time spent at school since the marginal productivity of $e$ is larger when $q$ increases. Second, households can attain the same income in the second period by devoting less time to school and therefore have an incentive to decrease $e$. The lower is $q$, the larger is the second effect. Propositions 2 and 3 state the results obtained when these effects are combined. 
Proposition 2 When education quality is very low, an increase in quality never enhances efficiency for constrained households.

Proof. Plugging (16) into (15) and manipulating the resulting expression, we obtain:

$$
w h_{e q}\left(e_{c}, q\right)<\underbrace{\frac{\left(w h_{q}\left(e_{c}, q\right)-\lambda e_{c}\right) w h_{e}\left(e_{c}, q\right) w h_{e e}\left(e_{c}, q\right) U^{\prime \prime}\left(c_{2 c}\right)}{D}}_{A<0}+\underbrace{\frac{w h_{e e}\left(e_{c}, q\right) U^{\prime}\left(c_{2 c}\right)}{D}+1}_{B>0},
$$

where $D \equiv(w+\kappa-\theta)^{2} U^{\prime \prime}\left(c_{1 c}\right)+\left(w h_{e}\left(e_{c}, q\right)\right)^{2} U^{\prime \prime}\left(c_{2 c}\right)<0$. By the assumptions on the human capital production function, when quality is very low, $A \rightarrow-\infty$, and (17) cannot be satisfied.

When education quality is very low, Proposition 2 shows that the household always decreases time spent at school, even if $e$ and $q$ are complements. Since the marginal productivity of $q$ is very large when $q$ is low, the household can achieve the same income in the second period by devoting less time to school when $q$ increases. As explained before, the efficient level of $e$ is also affected. When $e$ and $q$ are complements, increased quality raises the efficient level of $e$, moving it further away from the households. Since the efficient level of time spent at school increases and the actual time spent at school decreases, the inefficiency unambiguously increases. When $e$ and $q$ are substitutes, increased quality decreases the efficient level of time spent at school. If $q$ is very low, the decrease in time spent at school by constrained households is larger than the reduction in the efficient level of $e$. Thus, inefficiency always increases.

More generally, when $q$ is low enough so that $A+B<0$, inefficiency can be reduced only if $e$ and $q$ are sufficiently strong substitutes: $h_{e q}(e, q)<A+B$. In this case, credit constrained households still reduce the time their children spend at school, as a response to the increase in $q$. However, due to the strong substitutability between $e$ and $q$, the efficient amount of time falls still more and, therefore, inefficiency can in principle be reduced.

Proposition 3 states the effects of increasing quality on efficiency when quality approaches its optimal level.

Proposition 3 When education quality approaches its optimal level, an increase in quality always enhances efficiency for constrained households provided that time spent at school and education quality are substitutes, or weak complements.

Proof. When quality approaches its optimal value, $w h_{q}(e, q)-\lambda e_{c} \rightarrow 0, A$ tends to zero and $A+B>0$. Condition (17) is always satisfied for $h_{e q}(e, q)<0$. Thus, raising $q$ always 
reduces inefficiency when $e$ and $q$ are substitutes. When $h_{e q}(e, q)>0$, inefficiency will be reduced only if $h_{e q}(e, q)<A+B$, i.e., if time spent at school and quality are sufficiently weak complements.

When quality is close to its optimal level, the effect on second period net income tends to zero, so households have less incentives to reduce $e$ (second term in (16)). As a result, when $e$ and $q$ are substitutes, the reduction in time spent at school is less intense than when $q$ is low. In contrast, when $e$ and $q$ are complements, the increase in $e$ is larger than when $q$ is low. As already mentioned, the efficient level of $e$ decreases when $e$ and $q$ are substitutes or weak complements. In both cases, the actual and the efficient level of $e$ come closer to each other following an increase in $q$.

Therefore, increasing quality is never efficiency enhancing when quality is very low. Note that this is in spite of the fact that we assumed that increasing quality has a large effect on human capital when quality is very low. Indeed, in this case, households react by decreasing significantly the time their children spend at school and this increases inefficiency. We can conclude that CCT are best in terms of efficiency when quality is low and constrained households can be targeted.

\section{Welfare}

When focusing on welfare, we are concerned about the effect of these policies in terms of household utility as opposed to lifetime income. Clearly, an increase in net income improves welfare whether it is provided in the first or second period. When a policy implies a transfer of income between the two periods, its final effect depends crucially on the credit constraint. In this section, we focus on the effect of cash transfers and education quality on constrained household utility.

\subsection{Cash Transfers}

Using (1)-(4) with $q=f$ and $s=0$ and applying the envelope theorem, we obtain that an increase in UCT raises the welfare of constrained households:

$$
\frac{d U_{c}}{d v}=U^{\prime}\left(c_{1 c}\right)-\lambda U^{\prime}\left(c_{2 c}\right)>0
$$

This happens for two reasons. First, the UCT represents a net positive transfer to constrained households, since $\lambda<1$. Second, by transferring income from the second to the first period, 
where marginal utility is higher, the UCT relaxes the credit constraint. Thus, even if $\lambda=1$, implying that households pay in the second period the same amount they receive in the first period, an increase in UCT always increases welfare of constrained households by relaxing the credit constraint.

An increase in CCT also raises welfare of credit constrained households, but this effect is proportional to the amount of time their children spend at school:

$$
\frac{d U_{c}}{d \theta}=e_{c}\left(U^{\prime}\left(c_{1 c}\right)-\lambda U^{\prime}\left(c_{2 c}\right)\right)>0
$$

by the envelope theorem. As will be shown in Section 5, this unambiguously positive effect of CCT on constrained households' welfare relies on the fact that only constrained households receive the CCT. Proposition 4 summarizes the comparison of UCT and CCT for constrained households.

Proposition 4 In the presence of credit constraints, conditional and unconditional cash transfers have the same positive effect on household welfare if credit constrained households can be targeted.

Proof. From (18) and (19), an increase in CCT coupled with a decrease in UCT that leaves the government budget balanced, i.e., $d v=-e_{c} d \theta$, has no effect on household welfare:

$$
U_{c}^{\theta, v}=\left(\frac{d U}{d \theta}-\frac{d U}{d v} e_{c}\right) d \theta=0
$$

Since we consider changes in policy that leave the government budget constraint balanced, both UCT and CCT have the same effect in terms of income, i.e., the credit constraint is relaxed to the same extent in both cases. We have seen in Section 3 that UCT and CCT have different impacts on the choice of time spent at school. However, because households equalize marginal costs and benefits when choosing $e$, the final effect of the change from UCT to CCT on welfare is nil.

This conclusion can appear surprising in view of the results obtained previously in the literature, which suggest that UCT are always more welfare enhancing than CCT. On reason for our result is that, in our framework, households would take optimal decisions in the absence of credit constraints. Moreover, in our model, CCT change the unit price of education, while allowing households to choose the level of $e$ that equalizes marginal benefit and the 
marginal cost of time spent at school. ${ }^{16}$

\subsection{Education Quality}

We have discussed in Section 3 that increasing quality never reduces the inefficiency of constrained households' decisions when quality is very low, but always preserves the efficiency of unconstrained household decisions. In contrast, the effect on constrained household's welfare is unambiguously positive when quality is inefficiently low and tends to zero as quality approaches its optimal value.

Proposition 5 When education quality is low, increasing quality improves constrained household welfare. As education quality approaches its optimal level, the effect of increasing quality on welfare tends to zero.

Proof. Using (1)-(4) with $q=f$ and $s=0$ and applying the envelope theorem, we obtain:

$$
\frac{d U_{c}}{d q}=\left(w h_{q}\left(e_{c}, q\right)-\lambda e_{c}\right) U^{\prime}\left(c_{2 c}\right)>0
$$

under Assumption 1. If $w h_{q}\left(e_{c}, q\right)-\lambda e_{c} \rightarrow 0, \frac{d U_{c}}{d q} \rightarrow 0$.

The welfare effect for unconstrained households, who are also affected by the increase in $q$, is ambiguous, as shown in Appendix A. This is so because increasing education quality raises the cost of tuition in the first period, but increases net income in the second period. If it is positive, it is always smaller than the effect on constrained households welfare. Unlike the constrained, unconstrained households pay tuition costs and taxes, and they also have a lower marginal utility of second period consumption due to larger income.

Concerning constrained households, the welfare effect of increasing education quality and simultaneously reducing CCT in order to leave the budget balanced (i.e., $d q=-d \theta$ ) is trivial, given by (19) and (20). Increasing quality is more (less) welfare enhancing than CCT or UCT, when quality is low (high) relatively to the severity of the household credit constraint.

\footnotetext{
${ }^{16}$ Alternatively, CCT can be seen as a lump-sum transfer conditional on having achieved a pre-established threshold of time spent at school. In that case, the transfer may push household choice to a corner where satisfying the requirement and receiving the transfer is better than not, but households would be better off if the transfer was not conditional on the amount of time spent at school. In our view, when studying households' choice over the lifetime, the number of periods over which the transfer is received is large and the first, continuous, approach is more appropriate.
} 


\section{Universal Policies}

In the analysis, we assumed that the government is able to target UCT, CCT, and free education exclusively at constrained households. When targeting cannot be achieved, some of our previous results need to be qualified. More importantly, the effect of the different policies on unconstrained household efficiency and welfare need to be taken into account. In this case, the government budget constraint becomes:

$$
T=v+\theta \bar{e}+q \bar{e}
$$

where $\bar{e}=\lambda e_{c}+(1-\lambda) e_{u}$ is the average level of time spent at school.

\section{$5.1 \quad$ Efficiency}

The effect of the different policies on the efficiency of constrained households behavior remains qualitatively the same as in Section 3. However, it is now unclear whether UCT or CCT is the best policy in terms of efficiency. On the one hand, CCT has a larger effect on behavior through the price effect. On the other hand, constrained households receive less with CCT than with UCT, since their children spend less time at school than the average. Using (21) and following the same procedure as before, the comparison of CCT and UCT yields:

$$
\Upsilon_{c}^{\theta, v}=-\frac{h_{e e}\left(e_{c}, q\right) U^{\prime}\left(c_{1 c}\right) d \theta+h_{e e}\left(e_{c}, q\right)(w+\kappa-\theta) U^{\prime \prime}\left(c_{1 c}\right)\left(\bar{e}-e_{c}\right) d \theta}{(w+\kappa-\theta)^{2} U^{\prime \prime}\left(c_{1 c}\right)+\left(w h_{e}\left(e_{c}, q\right)\right)^{2} U^{\prime \prime}\left(c_{2 c}\right)+w h_{e e}\left(e_{c}, q\right) U^{\prime}\left(c_{2 c}\right)}
$$

With respect to unconstrained households, we know that in the absence of policies, their decisions are efficient and given by (8). Since their savings are interior, we need to consider the effect of policies on the simultaneous choice of $e$ and $s$. Using Cramer Rule, it is easy to show that an increase in UCT has no effect on the time spent at school by children of unconstrained households. As a result, an UCT has no impact on efficiency. In contrast, an increase in CCT yields:

$\frac{d e_{u}}{d \theta}=\frac{-U^{\prime}\left(c_{1 u}\right)\left(U^{\prime \prime}\left(c_{1 u}\right)+U^{\prime \prime}\left(c_{2 u}\right)\right)+U^{\prime \prime}\left(c_{1 u}\right) U^{\prime \prime}\left(c_{2 u}\right)\left(e_{u}-\bar{e}\right)\left(w+\kappa-\theta-w h_{e}\right)}{\left(U^{\prime \prime}\left(c_{1 u}\right)+U^{\prime \prime}\left(c_{2 u}\right)\right) w U^{\prime}\left(c_{2 u}\right) h_{e e}\left(e_{u}, q\right)+U^{\prime \prime}\left(c_{1 u}\right) U^{\prime \prime}\left(c_{2 u}\right)\left(w+\kappa-\theta-w h_{e}\left(e_{u}, q\right)\right)^{2}}$.

Using (8) and simplifying:

$$
\frac{d e_{u}}{d \theta}=-\frac{1}{w h_{e e}\left(e_{u}, q\right)}>0 .
$$

Thus, unconstrained households increase the time their children spend at school following and 
increase in CCT. This leads to an inefficient behavior since the left-hand side of expression (8) decreases while the right-hand side remains unchanged. As a result of CCT, unconstrained households over-invest in education with respect to the efficient level.

Similarly, if unconstrained households benefit from free tuition, they over-invest in education. When education quality increases, they adjust their behavior. We can show that the inefficiency of the time spent at school by children of unconstrained households increases since they do not face the true costs of the quality increase when they receive free tuition. ${ }^{17}$

Summarizing, when constrained households cannot be perfectly targeted, it is no longer true that CCT is unambiguously superior to UCT in terms of efficiency. Since constrained households spend less time at school than unconstrained households, they receive less income under CCT than UCT. This undermines the positive effects of CCT on efficiency and makes UCT superior to CCT in terms of welfare for constrained households. For unconstrained households, UCT is neutral in terms of efficiency and CCT enhances the inefficiency. Also, if unconstrained households benefit from free tuition, they over-invest in education. Increasing education quality in this case only aggravates the inefficiency of this decision.

\subsection{Welfare}

As before, accounting for unconstrained households in the government budget constraint changes some of the welfare results we obtained when constrained households could be perfectly targeted. In particular, the results remain qualitatively unchanged for UCT and education quality:

$$
\begin{gathered}
\frac{d U_{c}}{d v}=U^{\prime}\left(c_{1 c}\right)-U^{\prime}\left(c_{2 c}\right)>0 . \\
\frac{d U_{c}}{d q}=U^{\prime}\left(c_{2 c}\right)\left(w h_{q}\left(e_{c}, q\right)-\bar{e}\right)>0 .
\end{gathered}
$$

However, allowing for heterogeneity in the recipients of CCT implies that those who spend less time at school end up receiving less than they pay in taxes. As a result, the effect on constrained households' welfare becomes ambiguous if they are not the only beneficiaries of CCT:

$$
\frac{d U_{c}}{d \theta}=U^{\prime}\left(c_{1 u}\right) e_{c}-U^{\prime}\left(c_{2 u}\right) \bar{e} .
$$

\footnotetext{
${ }^{17}$ The proof is similar to the one in Appendix A, but accounts for the fact that unconstrained households also receive free education.
} 
For unconstrained individuals, the optimal choices of both $e$ and $s$ are interior and, by the envelope theorem:

$$
\begin{gathered}
\frac{d U_{u}}{d v}=U^{\prime}\left(c_{1 u}\right)-U^{\prime}\left(c_{2 u}\right)=0 . \\
\frac{d U_{u}}{d \theta}=\left(e_{u}-\bar{e}\right) U^{\prime}\left(c_{1 u}\right)>0 . \\
\frac{d U_{u}}{d q}=U^{\prime}\left(c_{2 u}\right)\left(w h_{q}\left(e_{u}, q\right)-\bar{e}\right)>0 .
\end{gathered}
$$

The effect of UCT on the welfare of unconstrained individuals is zero, since they receive in the first period the same amount they pay in the second period and they are not constrained, i.e., $U^{\prime}\left(c_{1}\right)=U^{\prime}\left(c_{2}\right)$. An increase in CCT has a positive impact on unconstrained household's welfare because their children spend more time at school than children of constrained households. Finally, the effect of raising quality on unconstrained households welfare is positive, but smaller than the effect on constrained households due to a lower marginal utility of consumption in the second period. Thus, increasing quality has an unambiguously positive effect on the welfare of all households, larger for the constrained than for the unconstrained households.

\section{Conclusion}

In this paper, we investigate the impact on efficiency and welfare of three alternative policies - UCT, CCT and improvements in education quality - aimed at households that spend an inefficiently low amount of time at school due to credit constraints. When constrained households can be perfectly targeted, we show that CCT are more efficiency enhancing than UCT because they not only relax the credit constraint, but they also change the unit price

of education. In contrast, for a given budget, both cash transfers are equivalent in terms of welfare.

Improving education quality, by investing in schools, teachers, or any education input other than time spent at school, also increases welfare when education quality is inefficiently low, as in poor developing countries. However, the effects of improving education quality in terms of efficiency are less clear cut. When education quality is very low, the inefficiency can never be reduced by increasing education quality. As quality approaches its optimal level, the impact of improving education quality on welfare becomes small. Then, raising education 
quality enhances efficiency, except if time spent at school and education quality are strong complements. We conclude that CCT are best in terms of efficiency when quality is low and constrained households can be targeted.

We also show that these results rely on the assumption of perfect targeting. Indeed, when the government cannot perfectly distinguish constrained from unconstrained households, UCT could be the best policy in terms of efficiency and welfare.

In our model, time spent at school is a continuous variable and CCT, paid by unit of time, change the price of education. This is the most appropriate approach when considering decisions over the lifetime, as we do in this paper. Alternatively, CCT could be conditioned on achieving a pre-determined threshold of school participation. In this case, households decisions could be distorted at the margin and the equivalence of CCT and UCT in terms of welfare, when constrained households can be targeted, would no longer hold. ${ }^{18}$

We have considered a very simple structure of taxation with uniform lump-sum taxes. This has the advantage of isolating the impact of expenditures from any distortive effect of taxation. It would be interesting to consider alternative sources of revenue more specific to developing countries. We leave these issues for future research.

\section{References}

Aker, J. and Ksoll, C. (2011). Why do some school inputs improve skills and others do not? Evidence from Niger. mimeo.

Attanasio, O., Battistin, E., Fitzsimons, E., Mesnard, A., and Vera-Hernandez, M. (2005). How effective are conditional cash transfers? Evidence from Colombia. Institute for Fiscal Studies Briefing Note, 54.

Baland, J. M. and Robinson, J. A. (2000). Is child labor inefficient. Journal of Political Economy, 108(4):663-679.

Behrman, J. R., Sengupta, P., and Todd, P. (2005). Progressing through Progresa: An impact assessment of a school subsidy experiment in rural Mexico. Economic Development and Cultural Change, 54(1):237-275.

\footnotetext{
${ }^{18}$ In the literature on transfers between different levels of government, a difference is made between matching and non-matching conditional grants. While the former involves a change in the relative price of the conditioned good, the latter is a transfer of income once a discrete threshold in the consumption of that good is met. The same parallel can be made here, even if a similar distinction is not made in the CCT literature.
} 
Besley, T. and Coate, S. (1991). Public provision of private goods and the redistribution of income. American Economic Review, 81(4):979-984.

Bourguignon, F., Ferreira, F. H. G., and Leite, P. G. (2003). Conditional cash transfers, schooling, and child labor: Micro-simulating Brazil's Bolsa Escola program. The World Bank Economic Review, 17(2):229-254.

Coady, D. P. and Parker, S. W. (2004). Cost-effectiveness analysis of demand - and supplyside education interventions: The case of PROGRESA in Mexico. Review of Development Economics, 8(3):440-451.

Das, J., Do, Q.-T., and Ozler, B. (2005). Reassessing conditional cash transfer programs. The World Bank Research Observer, 20(1):57-80.

de Brauw, A. and Hoddinott, J. (2010). Must conditional cash transfer programs be conditioned to be effective? The impact of conditioning transfers on school enrollment in Mexico. Journal of Development Economics, forthcoming:1-12.

de Janvry, A. and Sadoulet, E. (2004). Conditional cash transfer programs: Are they really magic bullets? ARE Update, 7(6):9-11.

Dubois, P., de Janvry, A., and Sadoulet, E. (2008). Effects on school enrollment and performance of a conditional transfers program in Mexico. Department of Agricultural $\mathcal{B}^{3}$ Resource Economics, UC Berkeley, Working Paper Series.

Ferreira, F. H. G., Filmer, D., and Schady, N. (2009). Own and sibling effects of conditional cash transfer programs: Theory and evidence from Cambodia. Policy Research Working Paper, 5001:1-41.

Gahvari, F. and Mattos, E. (2007). Conditional cash transfers, public provision of private goods, and income redistribution. American Economic Review, 97(1):491-502.

Glewwe, P. (1999). The Economics of School Quality Investments in Developing Countries: An Empirical Study of Ghana. Macmillan Press.

Hanushek, E. A. (1995). Interpreting recent research on schooling in developing countries. The World Bank Research Observer, 10(2):227-246.

Hanushek, E. A. (2006). Handbook of the Economics of Education, chapter 14, School Resources, pages 865-908. New York: Elsevier. 
Hanushek, E. A. and Rivkin, S. G. (2006). Handbook of the Economics of Education, chapter 18, Teacher Quality, pages 1051-1078. New York: Elsevier.

Hicks, J. (1970). Elasticity of substitution again: Substitutes and complements. Oxford Economic Papers, 22(3):289-296.

Lipsey, R. G. and Lancaster, K. (1956). The general theory of second best. The Review of Economic Studies, 24(1):pp. 11-32.

Lockheed, M. E. and Verspoor, A. M. (1991). Improving primary education in developing countries. Oxford University Press.

Maluccio, J. A. and Flores, R. (2005). Impact evaluation of a conditional cash transfer program: The Nicaraguan Red de Protección Social. Technical report, International Food Policy Research Institute.

Martinelli, C. and Parker, S. W. (2003). Should transfer to poor families be conditional on school attendance? A household bargaining perspective. International Economic Review, $44(2): 523-544$.

Rawlings, L. B. and Rubio, G. M. (2005). Evaluating the impact of conditional cash transfer programs. The World Bank Research Observer, 20(1):29-55.

Reimers, F., da Silva, C. D., and Trevino, E. (2006). Where is the "education" in conditional cash transfers in education? UIS Working Paper, 4.

Schady, N. and Araujo, M. C. (2006). Cash transfers, conditions, school enrollment, and child work: Evidence from a randomized experiment in Ecuador. World Bank Policy Research Working Paper, 3930:1-30.

Schultz, T. P. (2004). School subsidies for the poor: Evaluating the Mexican Progresa poverty program. Journal of Development Economics, 74(1):199-250.

Skoufias, E. and Parker, S. W. (2001). Conditional cash transfers and their impact on child work and schooling: Evidence from the PROGRESA program in Mexico. Economia, 2(1):45-96.

Souza, A. P. and Cardoso, E. (2009). Child Labor and Education in Latin America: An Economic perspective, chapter The Impact of Cash Transfers on Child Labour and School Enrollment in Brazil. Palgrave Macmillan. 
Todd, P. E. and Wolpin, K. I. (2006). Assessing the impact of a school subsidy program in Mexico: Using a social experiment to validate a dynamic behavioral model of child schooling and fertility. American Economic Review, 96(5):1384-1417.

\section{A Education Quality: Unconstrained Decisions}

In the absence of policy intervention, unconstrained households take efficient decisions characterized by (8). Following the increase in quality, unconstrained households react by adjusting the time their children spend at school. Since their savings decision is interior, we need to account for the simultaneous effect of $q$ on $e$ and $s$. Let $e_{u}$ be the choice of time spent at school by unconstrained households. The effect of $q$ on $e_{u}$ is given by:

$$
\frac{d e_{u}}{d q}=\frac{\left|\begin{array}{cc}
-\frac{\partial^{2} U_{u}}{\partial e \partial q} & \frac{\partial^{2} U_{u}}{\partial s \partial e} \\
-\frac{\partial^{2} U_{u}}{\partial s \partial q} & \frac{\partial^{2} U_{u}}{\partial s^{2}}
\end{array}\right|}{\left|\begin{array}{ll}
\frac{\partial^{2} U_{u}}{\partial e^{2}} & \frac{\partial^{2} U_{u}}{\partial s \partial e} \\
\frac{\partial^{2} U_{u}}{\partial e \partial s} & \frac{\partial^{2} U_{u}}{\partial s^{2}}
\end{array}\right|}
$$

or, after some manipulation:

$$
\begin{aligned}
\frac{d e_{u}}{d q}= & \frac{\left(U^{\prime \prime}\left(c_{1 u}\right)+U^{\prime \prime}\left(c_{2 u}\right)\right)\left(U^{\prime}\left(c_{1 u}\right)-w U^{\prime}\left(c_{2 u}\right) h_{e q}\left(e_{u}, q\right)\right)}{\left(U^{\prime \prime}\left(c_{1 u}\right)+U^{\prime \prime}\left(c_{2 u}\right)\right) w U^{\prime}\left(c_{2 u}\right) h_{e e}\left(e_{u}, q\right)+U^{\prime \prime}\left(c_{1 u}\right) U^{\prime \prime}\left(c_{2 u}\right)\left(w+\kappa+q-\theta-w h_{e}\left(e_{u}, q\right)\right)^{2}} \\
& -\frac{U^{\prime \prime}\left(c_{1 u}\right) U^{\prime \prime}\left(c_{2 u}\right)\left(\lambda e_{c}-w h_{q}\left(e_{u}, q\right)\right)\left(w+\kappa+q-\theta-w h_{e}\left(e_{u}, q\right)\right)}{\left(U^{\prime \prime}\left(c_{1 u}\right)+U^{\prime \prime}\left(c_{2 u}\right)\right) w U^{\prime}\left(c_{2 u}\right) h_{e e}\left(e_{u}, q\right)+U^{\prime \prime}\left(c_{1 u}\right) U^{\prime \prime}\left(c_{2 u}\right)\left(w+\kappa+q-\theta-w h_{e}\left(e_{u}, q\right)\right)^{2}} .
\end{aligned}
$$

Differentiating (8) with respect to $q$ and simplifying:

$$
\frac{d I_{u}}{d q}=\frac{-U^{\prime}\left(c_{2 u}\right)+U^{\prime}\left(c_{1 u}\right)}{U^{\prime}\left(c_{2 u}\right)}=0,
$$

by (6). Thus, following the increase in $q$, unconstrained households adapt the time their children spend at school and this decision remains efficient. With respect to the effect on welfare, we have:

$$
\frac{d U_{u}}{d q}=-e_{u} U^{\prime}\left(c_{1 u}\right)+\left(w h_{q}\left(e_{u}, q\right)-\lambda e_{c}\right) U^{\prime}\left(c_{2 u}\right)
$$

using (1)-(4) with $f=0$ and applying the envelope theorem. The welfare effect of an increase in $q$ for unconstrained households is ambiguous when they do not benefit from free tuition. 